\title{
A FORMAÇÃO DE PROFESSORES E DE PESQUISADORES EM ADMINISTRAÇÃO: CONTRADIÇÕES E ALTERNATIVAS
}

\author{
THE TRAINING OF PROFESSORS AND RESEARCHERS IN ADMINISTRATION: \\ CONTRADICTIONS AND ALTERNATIVES
}

\author{
Roberto Patrus \\ PUC Minas \\ robertopatrus@pucminas.br \\ Manolita Correa Lima \\ Escola Superior de Propaganda e Marketing - ESPM \\ mclima@espm.br
}

Submissão: $23 / 07 / 2013$

Aprovação: 25/01/2014 (Trabalho convidado)

\section{RESUMO}

O objeto deste ensaio é a formação do professor e do pesquisador no âmbito dos cursos stricto sensu em Administração. Em tese, os programas de pós-graduação stricto sensu devem contribuir para formar professores e pesquisadores críticos, capazes de refletir e compreender o processo educativo e a epistemologia do conhecimento, seus limites, métodos e possibilidades. Entretanto, eles estão prioritariamente voltados para a formação do pesquisador e visivelmente distantes da formação pedagógica. Tal lacuna na concepção do professor de Administração exige a reflexão sobre alternativas para sua formação pedagógica. Entre elas, reconhecendo o papel indutivo da avaliação da CAPES, propõe-se o estímulo à criação de linhas de pesquisa em Ensino e Aprendizagem em Administração. Também se reivindica maior atuação política dos professores, coordenadores de curso e associações que os representam, entre elas a ANPAD - Associação Nacional de Pós-graduação e Pesquisa em Administração.

Palavras-chave: Formação do professor. Formação do pesquisador. CAPES. Avaliação. 


\begin{abstract}
The object of this essay is the education of teachers and researchers in Master's and Ph.D. in Business Administration. In theory, post-graduate programs should help to educate critical teachers and researchers able to reflect and understand the educational process and epistemology of knowledge, its limits, methods and possibilities. However, they are primarily focused on research and visibly far from the pedagogical dimension of formation. This gap in the teacher's education requires alternatives to their pedagogical formation. Among them, recognizing the inductive role of CAPES assessment, it is proposed to encourage the creation of lines of research in Teaching and Learning in Management. It also calls for more political involvement of professors, course coordinators and associations that represent them, including ANPAD National Association of Post-Graduate Studies and Research in Administration.
\end{abstract}

Keywords: Teacher education. Researcher education. CAPES. Assessment. 


\section{CONTEXTUALIZAÇÃO E PROBLEMATIZAÇÃO}

Neste ensaio teórico pretendemos uma comunicação capaz de provocar o leitor e mobilizá-lo em sua subjetividade, para concordar ou discordar com o movimento reflexivo que ocorre no percurso da leitura (MENEGHETTI, 2011a, p. 331). Tal reflexão se vale da subjetividade dos autores, que se permitem posicionar-se criticamente acerca do fenômeno, a fim de submeter seu pensamento "ao crivo de outrem" (BARROS, 2011, p. 335). Embora a ambição do texto alinhar-se ao que Bertero (2011, p. 341) nomeou de grande imprudência, aceitamos o convite de Meneghetti (2011b, p. 348) a permanecer com tal (im)postura, recorrendo ao sentido de um ensaio como "tentativa de ação especulativa e interpretativa" (BARROS, 2011, p. 335).

O objeto da reflexão proposta é a formação docente do professor no âmbito dos cursos stricto sensu em Administração, oferecidos no Brasil. Parafraseando Gusdorff (1970), perguntamos: mestres e doutores, para quê? Em tese, eles contribuiriam para formar pessoas e profissionais, ou seja, professores e pesquisadores capazes de refletir sobre sua vida e seu trabalho, além de compreender o processo educativo e a epistemologia do conhecimento, seus limites, métodos e possibilidades. Entretanto, os programas de pós-graduação estão prioritariamente voltados para a formação de pesquisadores e visivelmente distantes da formação pedagógica, sobretudo da formação da consciência reflexiva e da capacidade crítica (VEIGA, 2005), uma vez que historicamente a política que orienta a condução de ações voltadas para a formação de professores para a educação superior no Brasil permanece tímida (MOROSINI, 2000). Assim, a formação para a docência no ensino superior e o amadurecimento emocional do profissional tem permanecido sob os cuidados dos próprios docentes e de iniciativas isoladas de poucos programas de pós-graduação. Os currículos dos cursos de stricto sensu não enfatizam a formação para além dos saberes e competências relativos à pesquisa (ZANCHET; GHIGGI, 2009).

Estudiosos de expressão mundial contribuíram para a discussão do conceito de formação ou processo de formação (bildung). Destacam-se, particularmente, Adorno (1995), Humboldt (1997) e Fichte (1999). Mas, reveladoramente, ao tratar da formação de docentes para o exercício do magistério superior, o conteúdo da LDB (BRASIL, 1996) utiliza o termo preparação (... a preparação para o exercício do magistério superior...). Nessa direção, duas observações parecem Revista Economia \& Gestão - v. 14, n. 34, jan./mar. 2014 
cabíveis: enquanto formação é um conceito, preparação é apenas um termo; enquanto formação pressupõe um processo, preparação remete a algo pontual, localizado, específico - preparar uma aula, uma prova, slides de uma exposição ou algo similar.

Parece-nos relevante, ainda, relacionar o desafio da formação do professor nos cursos de mestrado e doutorado com o caráter performático da avaliação da CAPES, órgão responsável pela regulação e avaliação dos programas stricto sensu. Sintomaticamente, a referida avaliação reconhece a produção intelectual como a principal medida de qualidade da pós-graduação. Ela não reconhece ações voltadas para a formação e valorização do docente. Nessa trilha, a atividade de ensino parece atrapalhar a pesquisa, razão pela qual, não raro, é encarada como os ossos do ofício. Mas, apesar da dificuldade de encontrar cursos de pós-graduação stricto sensu comprometidos com a formação de docentes, paradoxalmente, um dos aspectos avaliados como de maior impacto na qualidade dos cursos de graduação é a prática docente, particularmente a pertinência dos recursos didáticos explorados pelos professores (PACHANE; PEREIRA, 2004; SINAES, 2009).

A esse quadro, acrescentamos outras duas justificativas de ordem prática para a discussão proposta. Primeiramente, o mestrado profissional tem formado mestres que se ocupam da atividade docente em instituições de ensino superior. Resultados de uma pesquisa realizada com egressos de um mestrado profissional em Administração, por exemplo, revelou que, concluído o curso, a maior parte deles passou a trabalhar como professor universitário (TEIXEIRA; OLIVEIRA; FARIA, 2007). Essa constatação apenas reforça o número de egressos dos cursos de graduação e experientes profissionais do mercado, levados por distintas motivações, a assumirem responsabilidades docentes (SOUZA-SILVA; DAVEL, 2005), mesmo sem tempo para se familiarizar com conceitos próprios da educação superior. Em segundo lugar, as universidades privadas de caráter comunitário têm limitada capacidade de encaminhar os professores doutores para seus programas de pós-graduação, uma vez que, não raro, o número de doutores em seus quadros se mostra superior à capacidade de a instituição alocá-los em um de seus programas stricto sensu. A questão é particularmente intrigante quando se leva em consideração dados sobre a distribuição dos doutores titulados no Brasil, por seção da Classificação Nacional de Atividades Econômicas (CNAE) dos estabelecimentos empregadores: mais de três quartos $(76,77 \%)$ daqueles titulados no intervalo de dez anos (1996 e 2006) e empregados durante 2008, permaneceram no setor educacional (CENTRO DE GESTÃO E ESTUDOS ESTRATÉGICOS, 
2010, p. 222). Mas até que ponto o aumento do número de doutores tem exercido influência na produção acadêmica e na qualidade do ensino, simultaneamente?

De acordo com a LDB (BRASIL, 1996), o aspecto que diferencia universidades de nãouniversidades é a não dissociação entre ensino, pesquisa e extensão. Por isso mesmo, as universidades são em número reduzido, quando comparadas às não-universidades. Na prática, grande parte das instituições não-universitárias prioriza a graduação e, quando oferece pósgraduação, os cursos estão inscritos na modalidade lato sensu. Assim sendo, tais instituições estão orientadas para e pelo ensino. No entanto, a organização dos programas de mestrado e doutorado está orientada para e pela pesquisa. Consequentemente, seus egressos estão mais familiarizados com as atividades de pesquisa do que de ensino. Contudo, profissionalmente, mestres e doutores terão mais chance de se vincular às não-universidades do que às universidades, instituições onde predomina a atividade de ensino - mas até que ponto as competências desejadas de pesquisadores coincidem com aquelas esperadas dos professores?

O cenário então parece ser o seguinte: cada vez formamos mais mestres em Administração (seja em cursos profissionalizantes ou acadêmicos). Grande parte desses mestres passa a lecionar em instituições com pouca ou nenhuma dedicação à pesquisa - principalmente quando se trata de instituições particulares, com foco no ensino. Os cursos de pós-graduação enfatizam a necessidade da produção intelectual, inclusive discente, materializada na publicação de artigos em revistas classificadas no Sistema Qualis/CAPES. Tais cursos, em geral, não dispõem de disciplinas ou estágios voltados para a formação docente. Toda a formação metodológica é direcionada para aspectos pertinentes ao exercício da pesquisa. A sala de aula não é objeto de reflexão, o docente universitário dorme profissional de uma área e acorda professor (SACRISTÁN, 1998; ANASTASIOU, 2006), apesar de sabermos que um pesquisador reconhecido não garante um excelente desempenho pedagógico (PIMENTA; ANASTASIOU, 2002). Reforça-se, assim, lamentável separação entre ensino e pesquisa, mesmo entre as universidades que dispõem de pós-graduação stricto sensu (DEMO, 2002). Se, por um lado, o sistema de educação superior brasileiro abriga instituições exclusivamente de ensino, em que os docentes não realizam pesquisa; por outro, há instituições que trabalham predominantemente com pesquisadores que veem o ensino como atividade de menor valor (FESTINALLI, 2005).

Com a política de expansão do ensino superior privado durante o governo FHC (jan. 1995-jan. 2003), dois aspectos pesam sobre a demanda de profissionais com formação docente: o 
aumento da matrícula e a crescente heterogeneidade do público que ingressa nos cursos superiores. É nesse contexto que, quatro décadas depois de criada a pós-graduação no País, a CAPES passa a interferir sobre a formação de professores universitários ao instituir o estágio docência (1999/2000). Mas essa medida atinge todos os programas stricto sensu, mestrandos e doutorandos? Até que ponto os programas de mestrado e doutorado têm condições de conceber um estágio de docência consequente porque capaz de contribuir para a formação pedagógica dos participantes, sem perder de vista a diversidade de perfis: idade, interesse na prática da docência superior, experiência na docência superior (em que tipo de instituição - universidade ou nãouniversidade?; em que nível de formação - graduação ou pós-graduação lato e stricto sensu?; com qual vínculo empregatício - horista ou 40 horas? etc.), aproximação do estágio com a área de conhecimento em que trabalha e com o projeto de pesquisa em andamento? Tais programas dispõem de professores comprometidos com a formação pedagógica dos mestrandos e doutorandos? Até que ponto os referidos estágios foram instituídos como forma de solucionar problemas circunstanciais - reduzido quadro de docentes, entre as universidades públicas, ou necessidade de redução de custos fixos, entre as instituições particulares?

Ainda são poucos os programas de mestrado e doutorado que incluíram disciplinas e práticas associadas à formação docente em seus curricula, uma vez que o referido estágio é obrigatório apenas para os bolsistas da CAPES. Assim sendo, estimamos que a medida tem atingido limitado número de mestrandos e doutorandos, particularmente quando se considera a demanda por professores, oriunda da educação superior e do ensino médio, em todas as áreas de conhecimento, nas diversas regiões do País (BASTOS, 2007, p. 110). Levando-se em conta a época em que foi criado, não são poucos aqueles que associaram a instituição do estágio docência à conhecida carência de professores nas universidades federais. Mesmo em reputadas universidades, não é incomum que os orientadores transfiram para os orientandos a condução de (grande) parte das aulas, realização e avaliação da aprendizagem que estão sob sua responsabilidade, na graduação. $\mathrm{O}$ orientador acaba por delegar a seu orientando a sala de aula da graduação da qual é responsável, cabendo-lhe apenas assinar o diário, a ata de notas e frequência. Nesse caso, o estágio docente ocorre não como um momento de aprendizagem assistida, mas como um exercício de ensaio e erro, afinal, aprende-se fazendo! O orientador, por sua vez, ganha "liberdade" para se dedicar à pesquisa, escrever artigos, viajar para coletar dados, participar de 
congressos, ser professor visitante em outra instituição etc. Essa distorção leva Fischer (2006, p.195) a afirmar em tom que transita da desaprovação para a denúncia,

[...] o professor substituto que chega a uma sala de aula sem preparação adequada na organização e no desenvolvimento do ensino não está fazendo estágio; está exercendo a docência em caráter precário, o que pode ser contraproducente e voltar-se contra a formação pretendida. [...], substituir professores por alunos de pós-graduação afeta a qualidade do ensino de graduação e a formação de mestres na pós-graduação.

Diante desse panorama, procuraremos entender o processo de formação do docente de nível superior em Administração e relacionar as lacunas presentes nessa formação com o sistema de avaliação da CAPES. Além de instigar a reflexão sobre o tema, desejamos propor alternativas para a formação do professor universitário, em particular, dos cursos de Administração. Para isso, apropriamo-nos da fala de Fernandes (1998, p. 97), que argumenta a importância de se construírem pontes entre a dimensão epistemológica (a questão do conhecimento), a dimensão pedagógica (a questão de ensinar e aprender) e a dimensão política (a questão do projeto de sociedade e universidade que se pretende). A tese do ensaio é a de que os programas de pósgraduação em Administração oferecidos no Brasil priorizam a dimensão epistemológica em detrimento da pedagógica. E isso compromete a dimensão política da formação de mestres e doutores, como também sinaliza certa apatia dos programas de pós-graduação que se revelam cada vez mais resignados em virtude da perceptível cumplicidade impensada e pré-reflexiva (MACHADO; BIANCHETTI, 2011).

\section{A FORMAÇÃO DO PROFESSOR UNIVERSITÁRIO}

Apesar de a Constituição Brasileira (BRASIL, 1988) estabelecer o ensino, a pesquisa e a extensão como as funções básicas da universidade, na prática essas atividades foram fatiadas de tal modo que, enquanto os cursos de graduação e pós-graduação lato sensu estão orientados para a atividade de ensino (socialização de conhecimento), os programas de pós-graduação stricto sensu estão orientados para fomentar a atividade de pesquisa (produção de conhecimento). Com raras exceções, a não dissociação das três funções básicas da universidade tem permanecido um desafio na medida em que sua concretização depende de mudanças na cultura das instituições. Apesar de ser uma medida de relativo impacto, de alguma forma a instituição do estágio docente 
nos programas de mestrado/doutorado busca aproximar a graduação da pós-graduação stricto sensu e o ensino da pesquisa, afinal, os cursos de mestrado se comprometem a formar mestres.

Coerente com o ethos acadêmico da universidade, a LDB (BRASIL, 1996, art. 66) associa atividades de ensino e pesquisa ao determinar que a formação dos professores da educação superior estará prioritariamente - e não exclusivamente - assegurada nos cursos de mestrado e doutorado. ${ }^{1}$ No entanto, historicamente, a formação de pesquisadores tem preferência nos programas de pós-graduação. Isso é evidenciado pela obrigatoriedade de mestrandos realizarem a dissertação e doutorandos desenvolverem a tese, além da pressão que recebem para gerar publicação em anais e revistas acadêmicos. Para cumprir tais requisitos, os curricula dos cursos reforçam a formação científica com a inclusão de disciplinas e práticas voltadas para a formação do pesquisador. Tal constatação leva Fischer (2006, p. 194) assegurar que, apesar de os programas de mestrado e doutorado em Administração oferecerem disciplinas que promovem a formação do pesquisador, poucos incluem disciplinas e práticas voltadas à formação do professor.

No Brasil, a preocupação com a formação do professor surgiu em 1934, na Universidade de São Paulo, com a oferta dos cursos de licenciatura dirigidos para bacharéis de distintas áreas, orientados para o aprofundamento de conteúdos pedagógicos (PIMENTA; ANASTASIOU, 2002). Até a década de 1970, praticamente só se exigia do candidato a professor universitário o bacharelado e o exercício competente de sua profissão. Essa prática apoiava-se na crença de que quem sabe, sabe ensinar, principalmente porque ensinar significava ministrar aulas expositivas, reduzindo professores a porta-vozes das ideias alheias (DEMO, 2011). A visão de que a docência exige capacitação própria e específica e de que esta não se restringe a emissão de um diploma de bacharel ou ao exercício de uma profissão, é recente (MASETTO, 1998). Nessa perspectiva nos parece pertinente desenvolver uma reflexão sobre a formação do professor universitário. Diferentemente dos outros graus de ensino, historicamente esse professor tem se constituído, tendo como base a profissão paralela que exerce ou exercia no universo do trabalho.

Os programas de mestrado e doutorado estão organizados a partir da perspectiva da especialização, priorizando algum recorte do conhecimento. Assim, permanece subjacente o pressuposto de que para o exercício da docência basta o domínio do conhecimento específico,

\footnotetext{
${ }^{1}$ Ressalva feita por Selma Pimenta e Léa das Graças C. Anastasiou, em texto publicado pela Cortez, em 2005, intitulado Docência no ensino superior.

Revista Economia \& Gestão - v. 14, n. 34, jan./mar. 2014 
aliado a alguma competência para a atividade de pesquisa. Questionados sobre o que seria necessário saber para ensinar, professores ouvidos por Grillo e Mattei (2005) apenas reforçam essa tônica: conhecimento específico das disciplinas que lecionam! Da consideração de que a atividade de pesquisa é produção de conhecimento e da ideia de que a concepção de formação que vem presidindo o magistério de nível superior tem, na pesquisa, sua principal base (CUNHA, 2001, p. 45), podemos deduzir outro pressuposto, alinhado ao anteriormente apresentado: quem produz o conhecimento é capaz de transmiti-lo, desconsiderando as teorias da aprendizagem, particularmente as formuladas por Piaget (2007) e Vygotsky (1989). Tais pressupostos não nos parecem válidos, embora sejam premissas a partir das quais se constroem os modelos dominantes de avaliação de professores, cursos e programas de pós-graduação. A falácia pode ser argumentada a partir da distinção teórica entre ensino e pesquisa e de alguns elementos práticos.

Do ponto de vista prático, o sofisma se mostra evidente tanto pela dificuldade de alguns pesquisadores em escrever textos de uma forma compreensível a estudantes de graduação, quanto pela dificuldade didática apresentada no processo dialético estabelecido na sala de aula com os alunos. $\mathrm{O}$ fato de ter professores doutores não se apresenta como condição suficiente para o aprendizado dos alunos, embora seja uma condição necessária. Os próprios estudantes de pósgraduação que estão legalmente habilitados ao exercício da docência, muitas vezes, não se sentem capacitados para tal. Resultados de pesquisa realizada por Macedo, Paula e Torres (1998), com estudantes de pós-graduação da USP, revelaram que eles próprios se sentem pedagogicamente despreparados para a docência e que esta é a principal crítica que fazem à sua própria formação. Devido à falta de experiência e formação inadequada, ao ingressarem em atividades de ensino, os pós-graduandos acabam por reproduzir o sistema pedagógico vigente, não contribuindo para a renovação do processo educacional. Resultados da pesquisa conduzida por Chamlian (2003), tendo os professores da USP como interlocutores, corroboram as conclusões de Macedo, Paula e Torres (1998), apesar de se tratar de experientes docentes e não de estudantes de pós-graduação.

Do ponto de vista teórico, valemo-nos das cinco variáveis propostas por Pimenta e Anastasiou (2002) para estabelecer a distinção entre ensino e pesquisa: sujeitos envolvidos, tempo, resultados, conhecimentos e método. No que diz respeito aos sujeitos envolvidos, recorrentemente o trabalho de pesquisa é desenvolvido individualmente, enquanto, no ensino, o professor está constantemente envolvido com outros sujeitos - estudantes, coordenadores, 

diretores e colegas docentes, dentre outros. Com relação ao tempo, não raro, este pode ser alterado na pesquisa, enquanto o processo de ensino precisa se adequar ao período letivo - a necessidade de estar em sala em horários determinados, em dias fixos da semana, é bem diferente da necessidade de tempo exigido no processo de investigação, uma vez que pode mesclar momentos de maior e menor dedicação com outros de relativa flexibilidade de horário. Quanto aos resultados obtidos na pesquisa, eles dizem respeito aos conhecimentos gerados sobre o tema/problema investigado, podendo ou não corroborar a teoria existente. O ensino, por sua vez, proporciona como resultado, a aprendizagem dos estudantes por meio de novas elaborações e novas sínteses. Na pesquisa, o produto é a publicação, tangível e quantificável. No ensino, a aprendizagem é um produto bem menos tangível e que, em grande parte, depende da mobilização de outro sujeito (o estudante) e não somente da competência e comprometimento do professor. Quanto ao conhecimento, a atividade de pesquisa, principalmente em Administração, tende a ser criativa, ao passo que a atividade de ensino tende a ser reprodutiva. ${ }^{2}$ No ensino, o objeto de estudo é o conhecimento consagrado. Na pesquisa, parte-se desse conhecimento existente para coletar novos dados, elaborar novas interpretações e, de preferência, preencher lacunas presentes na literatura e na experiência profissional. No que diz respeito ao método, na pesquisa este é definido ao se formular o problema e depende do objeto e do campo do conhecimento. No ensino, a metodologia depende da visão de ciência, de conhecimento e de didática do professor. Apesar de ser implacável defensor do ensino com pesquisa, Demo (2011, p. 58) também argumenta que um "bom pesquisador não é automaticamente bom docente". Apesar de a competência da pesquisa colaborar para docência por colaborar para a formação de autores, "saber formar estudantes acarreta dimensões pedagógicas que não estão necessariamente incluídas na pesquisa" afinal, além da construção do conhecimento, a docência implica saber usar o processo reconstrutivo do conhecimento como base pedagógica.

Levando-se em conta as diferenças destacadas, parece claro que um pesquisador que contribui com expressivos acréscimos às concepções teóricas existentes não tem necessariamente um bom desempenho pedagógico. Exemplo disso é Max Weber. O sociólogo não dissimulava sua dificuldade com a atividade docente (COHN, 1991, p. 9-10). Pesquisa e docência são dois aspectos de uma formação que abrange ainda o desenvolvimento do profissional. Assim, os

\footnotetext{
${ }^{2}$ Essa é uma concepção de docência ultrapassada. O "bom professor" desenvolve elevada competência na desconstrução e reconstrução do conhecimento, revelando autonomia intelectual e competência autoral (DEMO, 2011).
}

Revista Economia \& Gestão - v. 14, n. 34, jan./mar. 2014 
programas de pós-graduação, ao priorizarem a formação do pesquisador, não promovem necessariamente a melhoria da qualidade docente dos mestres e doutores. Ou seja, esses cursos oferecem aos professores a titulação que, entretanto, não lhes confere necessariamente a competência para ensinar com qualidade. Para a docência, não basta o saber fazer ou o saber pesquisar. São também necessários a formação didático-pedagógica do professor universitário e o desenvolvimento pessoal. Urge construir as pontes entre as citadas dimensões epistemológica, pedagógica e política de que nos fala Fernandes (1998, p. 97). Inobstante, a concepção de formação que vem sendo enfatizada na docência tem na pesquisa seu principal alicerce. Segundo Zanchet e Ghiggi (2009), isso é reforçado pelos planos de carreira e pelos órgãos governamentais, que centram o parâmetro de qualidade dos cursos de pós-graduação na pesquisa, na publicação e na titulação.

\section{FORMAÇÃO DOCENTE EM ADMINISTRAÇÃO}

Historicamente, o desenvolvimento dos cursos superiores em Administração transita entre os interesses empresariais e a concepção de educação norte-americana. Nessa direção, os resultados de uma investigação conduzida por Souza-Silva e Davel (2005, p. 121), tendo como foco os cursos superiores de Administração em funcionamento no Brasil, pouco surpreendem. Com base em quatro categorias de professores - (a) alta experiência docente e alta vivência gerencial; (b) alta experiência docente e carência de vivência gerencial; (c) baixa experiência docente e alta vivência gerencial; e (c) baixa experiência docente e baixa vivência empresarial -, os autores concluem que a prática dos professores vinculados a cursos de Administração no País é mais próxima das práticas de mercado do que das práticas de ensino e pesquisa, uma vez que a presença de professores com alta experiência docente e alta vivência gerencial é modesta. Reveladoramente, a formação didático-pedagógica não integra as categorias trabalhadas pelos autores. Possivelmente tais resultados refletem as consequências da expansão desordenada da oferta de cursos de graduação em Administração no mercado educacional brasileiro: atração de professores com limitada formação acadêmica, nenhuma formação didático-pedagógica, pouca experiência docente e tímida vivência gerencial - perfil colocado em dúvida nas reflexões de Aktouf (2005). Dessa forma, compreende-se por que houve progressivo distanciamento entre ensino e pesquisa e a adoção de uma prática de ensino predominantemente bancária, nos termos 
de Freire (1987). Mesmo quando associou ensino e pesquisa, prevaleceu o que Ribeiro (2000) nomeia de monoglotismo científico. ${ }^{3}$

Compreensivelmente, o curso foi muito pouco renovado, os coordenadores se limitavam a cumprir as exigências impostas pelo currículo mínimo, estabelecido pelo Conselho Federal de Educação. Esse fato ajuda a entender o reduzido número de autores e textos que problematizaram a formação do Administrador, desde a concepção dos cursos superiores na área, até a bibliografia recomendada (MARANHÃO, 2010). Em texto de 2003, Nicolini associa os cursos de administração a fábricas de administradores e ressalta a dimensão autoritária da atividade docente na medida em que os professores não manifestavam preocupação de envolver os discentes em exercícios que se prestassem a refletir sobre a formação a que estavam submetidos. Conscientes ou não, eles reconheciam os discentes como produtos e não como sujeitos de sua própria formação. Mas não seriam os docentes, eles mesmos, produtos dessa fábrica de administradores? Adquiridos no mercado e de volta à linha de produção de onde saíram, apenas reproduziam o mesmo processo que os criou! E, se o mercado avaliava positivamente a qualidade dos produtos das fábricas de administradores, por qual motivo os professores investiriam tempo e esforços em problematizar ou em trilhar processos de autoformação e de transformação da realidade?

Reconhecendo a multidisciplinaridade como um ponto forte do curso de Administração e, ao mesmo tempo, entendendo que a formação substantiva de docentes para o magistério superior não pode decorrer de ações insulares, previstas nos cursos de mestrado e doutorado (a exemplo da oferta das disciplinas didática do ensino superior e estágio docência), tampouco de iniciativas isoladas de poucos programas, Fischer (2006, p. 196) chama a atenção para a necessidade de os programas de pós-graduação em Administração criarem linhas de pesquisa centradas em ensino $e$ aprendizagem em administração. E, ao defender essa prática, ela enfatiza a necessidade de se levarem em conta três aspectos: a transversalidade, a aplicabilidade e a integração de projetos e programas. A transversalidade requer a inclusão de projetos que aproximem estudantes e professores oriundos de distintos campos temáticos e linhas de pesquisa. Um programa que trabalhe com linhas de pesquisa em organizações, produção, tecnologia de informação, gestão de pessoas e finanças, por exemplo, pode ter uma linha de pesquisa que permeie essas áreas de

\footnotetext{
${ }^{3}$ Nos termos de Ribeiro (2001), monoglotismo científico ocorre quando o pesquisador se limita a utilizar os recursos disponibilizados por uma só língua - a ciência, por exemplo - quando se compromete a "ler o mundo"

Revista Economia \& Gestão - v. 14, n. 34, jan./mar. 2014 
conteúdo e discuta sobre 'como ensinar'. A aplicabilidade requer investigações orientadas para a formulação de soluções para problemas que traduzam os desafios implicados nas atividades de ensino e aprendizagem, sem desconsiderar as necessidades de requalificar as propostas de ensino da pós-graduação, de desenvolver reflexões e alternativas para os cursos de graduação. E a integração pressupõe a coordenação de esforços entre programas e comporta articulações interinstitucionais que viabilizem projetos coordenados. Esse conjunto de iniciativas tem inegável potencial de fortalecer o sistema de ensino de Administração, mas desmantela a lógica com que se tem trabalhado até então, em parte sob pressão do Ministério da Educação e da CAPES.

\section{A ÊNFASE NA DIMENSÃO EPISTEMOLÓGICA E OS CRITÉRIOS DE AVALIAÇÃO DA CAPES}

A avaliação da CAPES caracteriza-se por ser tipicamente externa, a partir de um sistema bastante compacto e centralizado, realizada de forma comparativa, conduzida por pares, cujo julgamento se baseia em um conjunto de dados sistematizados pela referida agência sobre o desempenho das unidades avaliadas (SPAGNOLO; SOUZA, 2004). Trata-se de uma avaliação "tipicamente acadêmica que valoriza, sobretudo, a pesquisa e as publicações científicas. Menor atenção é dada, tradicionalmente, ao ensino, à extensão, à cooperação com setores empresariais e governamentais, e ao impacto que as atividades desenvolvidas nos programas possam ter na sociedade em geral" (SPAGNOLO; SOUZA, 2004, p. 9).

Para Nascimento (2010, p. 591), a CAPES adotou a política de valorização do "produto final", o artigo científico, cuja qualidade é atestada pelos referees do periódico ao qual ele é submetido, sendo que a qualidade do periódico é indicada por seu fator de impacto. O autor preocupa-se com o "surto produtivista" resultante dessa concepção de avaliação. De fato, o lema publicar ou morrer (publish or perish) vem gerando textos requentados ou maquiados (KUENZER; MORAES, 2005), intensificação do trabalho docente (BIANCHETTI; MACHADO, 2009, p. 49), prejuízo da saúde física e mental dos pesquisadores (BIANCHETTI; MACHADO, 2009, p. 77) e orientação da gestão do programa para os critérios e indicadores que têm maior peso na avaliação da CAPES, o que não implica, necessariamente, melhoria da qualidade dos respectivos programas (SPAGNOLO; CALHAU, 2002). Nascimento (2010, p. 589) também chama atenção para os efeitos indesejados do modelo produtivista: a dificuldade de 
se encontrarem professores, principalmente nas universidades públicas, dispostos a se candidatar a cargos administrativos, a orientar graduandos, a participar de comissões e comitês da universidade, enfim a realizar atividades que "não irão somar pontos na avaliação individual do docente". O produtivismo acadêmico vem sendo objeto de crescentes críticas na medida em que promove a intensificação do trabalho docente (FIDALGO; FIDALGO, 2009), e substantivo aumento do estresse (PITA, 2010). Trein e Rodrigues (2011) remetem ao mal-estar na academia, a fetichização do conhecimento-mercadoria, termo também utilizado por Machado e Bianchetti (2011). Spink e Alves (2011) se referem ao campo turbulento da produção acadêmica (2011). Alcadipani (2011) compara o processo de produção do conhecimento com a produção em série de latas de sardinha. Para Cury (2010, p. 164), enfim, a gestão da pós-graduação no Brasil envolve a tensão entre a gestão burocrática à moda weberiana e o princípio da gestão democrática. Algumas instituições têm premiado os professores com um bônus em dinheiro no caso de uma publicação internacional classificada como Qualis A. Essa recompensa pode contribuir para que atividades administrativas e a necessária atitude solidária que permeia o ofício acadêmico fiquem em segundo plano. Porém, entre publicar ou morrer, alguns pesquisadores têm optado pela segunda alternativa. Um deles, reconhecido autor, professor e pesquisador, disse a um dos autores deste ensaio que renunciou a seu título de livre docente para tornar-se um docente livre.

As planilhas comparativas da Avaliação Trienal 2010 da CAPES (2011) corroboram esse dado. Seu conteúdo apresenta a relação de 96 cursos e programas de pós-graduação stricto sensu em Administração, caracterizados a partir da sigla da instituição, do curso, da modalidade do mestrado (acadêmico ou profissional), do ano de criação do mestrado e ou doutorado, e comparados de acordo com os seguintes critérios: nota final da avaliação trienal (de 7 a 3); número de docentes permanentes; número de dissertações e teses no triênio e da razão entre as duas; número de artigos completos publicados em periódicos técnico-científicos (de A1 a C); número de trabalhos completos publicados em anais de eventos técnico-científicos; número de livros e capítulos de livro; número de produções artísticas.

Considerando-se que a avaliação da CAPES é comparativa - o que inclui o conhecido sarrafo, termo utilizado entre os avaliadores mais antigos para expressar a existência de um número limite de cursos que podem atingir cada uma das notas, de acordo com a distribuição de uma curva normal, dois dados parecem significativos. O primeiro é o fato de uma planilha 
resumo publicada pela CAPES indicar apenas critérios de produção intelectual, incluindo entre eles a defesa de teses e dissertações no curso ou programa. O segundo é a objetividade da avaliação quando ela se limita ao registro de números. Esse dado aponta para um aspecto peculiar de uma avaliação comparativa: ela exige a quantificação e aquilo que não é quantificável não é avaliado.

Há de se reconhecer o papel indutor da avaliação, que, aliada a uma política pública, desempenha papel fundamental para impulsionar a realização de metas. Sem dúvida, a produção intelectual dos programas de pós-graduação tem aumentado significativamente. Também tem havido redução do tempo de conclusão de teses e dissertações. O Brasil aumentou sua participação na produção científica mundial. Um dos lados perversos dessa indução, porém, é fazer com que os programas de pós-graduação trabalhem apenas para atingir as metas estabelecidas pela avaliação. Como muitas possibilidades de financiamento estão associadas à nota alcançada na avaliação da CAPES, a gestão do programa passa a regular-se pelo que a CAPES estabelece como critério de avaliação. Ocorre aí importante obnubilação da autonomia universitária e da capacidade de gestão do programa. A pergunta fundamental sobre a missão de um programa de pós-graduação em Administração - que mestre ou doutor queremos formar? - é preterida em razão da necessidade de atender aos critérios de avaliação. Curiosamente, o produto se descola do processo que o realiza. E a dimensão política do programa desconsidera o caráter de construção de uma formação acadêmica e profissional. A dimensão pedagógica, como não é avaliada, é desconsiderada, é disso que o texto tratará na sequência.

\section{A ESQUECIDA DIMENSÃO PEDAGÓGICA}

Fischer (2006) assegura que os programas de pós-graduação estão pouco comprometidos com a formação do professor universitário; primeiro, porque não sabem como fazê-lo; segundo, porque ainda não é considerada prioritária para as instâncias reguladoras (CAPES), tampouco para os próprios programas. Afinal, como já foi argumentado, a avaliação da produtividade dos programas de pós-graduação está associada à produção e publicação de textos acadêmicos e não à participação em atividades de ensino. Essa constatação reitera o histórico prestígio conferido à pesquisa e o desprestígio impresso à docência (PACHANE; PEREIRA, 2004). Essa desimportância atribuída à formação de professores universitários leva pesquisadores do campo 

(DEMO, 2011; CUNHA, 2001; 2009; 1996; ANASTASIOU, 2003; 2006; MASETTO, 2003, entre outros) a assegurarem que historicamente a estrutura organizativa da educação superior do País privilegia o domínio de conhecimentos especializados e o acúmulo de experiências profissionais como pré-requisitos para o exercício do magistério. Adota-se como premissa que quem sabe, automaticamente sabe ensinar (MASETTO, 2003, p. 13). Nesse contexto, não é de se estranhar a naturalização da docência refletida nos resultados de pesquisas que investigaram a formação do professor universitário (JOAQUIM, 2011; CUNHA, 1996). Tais resultados revelam que sua história como estudante representa o fator que mais influencia a construção de sua prática docente. Nas palavras de Cunha (2009, p. 81), "para além das teorias pedagógicas que ele eventualmente aprende, o que marca o seu comportamento em sala de aula são as práticas utilizadas pelos seus antigos professores."

Nessa trilha, mesmo submetidos a rigoroso processo seletivo, ao ingressarem na USP, os professores que participaram da pesquisa realizada por Chamlian (2003) não se consideravam aptos para o exercício da docência. E, na tentativa de ultrapassarem a insegurança inicial, alguns procuraram imitar os professores que admiravam - reação que Cunha (1996) nomeia de ciclo da reprodução -, outros foram instruídos por seus orientadores ou colegas, alguns investiram na realização de cursos extracurriculares, outros, ainda, foram se iniciando aos poucos como docentes voluntários ou trabalhando em aulas práticas ou seminários (CUNHA, 1996, p. 8-9). Apesar da consistente formação teórica e da experiência docente acumulada, não foram poucos aqueles que se disseram insatisfeitos e manifestaram o desejo de aperfeiçoar ainda mais sua atuação docente (CHAMLIAN, 2003, p. 9). Essa situação permite se questionar a concepção linear da formação de professores e, ao mesmo tempo, reconhecer a importância da reflexão na construção do conhecimento profissional, tal como advogam autores de expressão na área (BOURDIEU, 1972; LIBÂNEO, 2002; PÉREZ GOMEZ，1992; SCHÖN，1992, 2000, entre outros).

A dimensão pedagógica da atuação do professor não se dissocia da epistemológica. $\mathrm{O}$ professor padrão é alguém que conhece sua área, a disciplina que leciona e o programa do curso (dimensão do conhecimento), familiarizado com conteúdos das ciências da educação e da pedagogia (dimensão pedagógica), sem deixar de desenvolver um saber prático, fundado na experiência cotidiana com os estudantes. A dimensão política, vista não no sentido original de Fernandes (1998), mas no sentido micro, pode ser pensada na perspectiva da gestão e 

administração da instituição em seus diversos setores, função do professor universitário, lembrada por Zabalza (2004). Neste ensaio, não contemplamos essa dimensão política, mas vale lembrar que ela também corresponde a uma faceta negligenciada. Participar de colegiados de coordenação didática, comitês de área, grupos de avaliação pressupõe atividades de gestão que poderiam ser objeto de avaliação dos programas, embora o seja nos processos de submissão de projetos para obtenção de bolsas de produtividade do CNPq.

\section{CONSIDERAÇÕES FINAIS}

A trajetória deste ensaio é uma tentativa de promover reflexões problematizadas sobre a formação docente do professor-pesquisador nos cursos de mestrado e doutorado em Administração. Sabemos que mais que um currículo formal, existe o currículo oculto e espaços de aprendizagem que extrapolam qualquer planejamento, afinal a formação de um adulto é uma conquista que se realiza com a ajuda de mestres, livros, aulas e computadores, mas depende sempre da mobilização para um trabalho pessoal (ZANCHETY; GHIGGI, 2009) ininterrupto. Trata-se de um processo emancipatório autônomo, marcado por fases e momentos nos quais atuam fatores sociais, políticos, pessoais, familiares, ora como facilitadores, ora como obstáculos. Ainda que o processo de formação seja um compromisso de cada professor com seu desenvolvimento pessoal e profissional, a organização de um curso (bem como a qualidade da relação entre orientador e orientando) é fator importante que pode favorecer ou dificultar a referida formação.

Procuramos refletir sobre a ênfase dada no processo de avaliação da CAPES, reconhecidamente centrada na dimensão epistemológica, do conhecimento. Possivelmente por isso, as instituições mais bem classificadas no ranking não sejam necessariamente as que melhor cumprem sua função social de ensino, pesquisa e extensão para a superação dos históricos déficits de igualdade e justiça social das sociedades em que se inserem ou aquelas que melhor formam seus estudantes, mestres e doutores (SGUISSARDI, 2010). Desconstruímos o pressuposto de que quem sabe um conteúdo sabe ensiná-lo, e, na mesma trilha, refutamos a ideia de que quem sabe fazer pesquisa sabe ensinar. Com isso, não queremos afirmar que o conhecimento sistematizado e profundo é desimportante, tampouco que a pesquisa é desnecessária ao ensino. Queremos reafirmar que a prioridade no conhecimento e na pesquisa 
vem promovendo o perigo de se considerar que o ensino (principalmente para a graduação) não é necessário àquele que se identifica e trabalha, a maior parte do tempo, como pesquisador. $\mathrm{E}$ fazemos coro ao alerta de Nascimento (2010), quando denuncia que já existem no âmbito dos programas de pós-graduação professores que não querem se dedicar à gestão dos programas ou das universidades, tampouco participar de comissões necessárias para a atividade acadêmica. Enfatizamos ainda que nem todos os mestres e doutores serão pesquisadores. Muitos deles aderem à carreira docente ou a outra atividade profissional e não terão oportunidade de realizar pesquisa e gerar publicação divulgada em periódicos classificados no Sistema Qualis.

Parece-nos claro que o produtivismo acadêmico subjacente ao sistema de avaliação da CAPES e alimentado por pesquisadores, pares, coordenadores, gestores e por aqueles que não querem perecer no sistema é um fator que vem contribuindo para a intensificação do trabalho docente, para o sofrimento psíquico dos professores, para a valorização da quantidade em detrimento da qualidade e para flagrante empobrecimento da formação de mestres e doutores. Ora, e a formação da dimensão pedagógica dos mestres e doutores? Será que ela só ganhará importância quando for transformada em indicadores e passar a fazer parte do sistema de avaliação? Será essa uma alternativa para a formação ou uma armadilha para tornar tangível e mensurável algo que extrapola a quantificação? É possível pensar um aperfeiçoamento que independa de avaliação? Cremos que aqui há uma oportunidade para inovação em gestão. Não existem respostas prontas, tampouco investimento para buscá-las, mas é urgente promover iniciativas que induzam esse investimento e abrir espaço para o debate propositivo dessa questão.

Ao escolher a avaliação do produto do processo de pesquisa (a publicação), presume-se que o processo foi bem realizado. Esse raciocínio pode ser colocado em dúvida a partir das reflexões aqui desenvolvidas. A finalidade de programa de pós-graduação não pode ser a publicação. Ela tem de servir ao desenvolvimento em todas as suas dimensões. O processo provoca efeitos colaterais sentidos por praticamente todos que participam do surto produtivista. Há elementos da atividade acadêmica que podem ser corroídos pela pressão por produtividade, entre eles, o cuidado com a formação de mestres e a dedicação à gestão acadêmica. Estrategicamente, para onde queremos levar a pós-graduação em Administração no País? Que tipo de profissional queremos formar? Que tipo de profissionais acadêmicos queremos ser?

Há um espírito colaborativo na academia que poderia ser valorizado. A exigência de solidariedade interinstitucional para que um programa receba as notas 6 ou 7 acaba por restringir- 
se aos programas mais antigos, com maior número de professores e, em geral, de universidades públicas, o que deveria ser um espírito universal de todos os cursos e programas. Um curso nota 5 de uma universidade particular tende, por exemplo, a não desenvolver mestrados interinstitucionais sob o risco de prejudicar a produção intelectual de seu (em geral reduzido) corpo docente. A valorização da solidariedade e da inserção social poderia ganhar peso maior na avaliação, dadas as assimetrias regionais da pós-graduação stricto sensu.

Uma estratégia promissora para o fomento de alternativas poderia ser a divulgação de um edital, com o propósito de induzir a pesquisa permanente com egressos dos cursos stricto senso em Administração, nos moldes do Pró-Administração realizado pela CAPES em 2009. A pesquisa contínua e o intercâmbio entre pesquisadores para a avaliação de egressos dos cursos promovem o processo intersubjetivo de diálogo na rede de pesquisadores sobre os caminhos dos mestres e doutores que os programas de pós-graduação estão formando. Além da produção discente e docente, poderíamos conceber a trajetória do egresso, não necessariamente sua produção intelectual, mas sua inserção, como mestre ou doutor, no mercado, nas IES, nas universidades, na vida.

Intercâmbio com programas de pós-graduação em Educação - espaço privilegiado de reflexão sobre a prática docente - pode ser uma alternativa. $\mathrm{O}$ incentivo ao intercâmbio de professores e alunos entre os cursos de mestrado e doutorado dos cursos de Educação e de Administração, intra ou interinstituições pode oxigenar a reflexão das duas partes e promover inovações interessantes. Integração do Qualis da Administração com o Qualis de outras áreas afins poderia facilitar esse intercâmbio e viabilizar produção conjunta entre diferentes programas. A busca por publicações em periódicos que tem Qualis da área de Administração (aqueles que "contam pontos") pode inibir o encaminhamento de trabalhos para periódicos que não estejam no Qualis das duas áreas envolvidas.

Também há de se ressaltar a importância da Associação dos Programas de Pós-graduação em Administração (ANPAD), uma vez que ela pode ser um fórum privilegiado de debate e discussão desse tema, pois reúne os coordenadores dos cursos e programas do país. Os encontros anuais da ANPAD podem ir além da mera apresentação de trabalhos e funcionar como um fórum de reflexão sobre a pesquisa, o ensino e a práxis. A ANPAD pode exercitar seu papel cidadão e ser uma voz ativa dos Programas que a constituem junto aos órgãos de governo. Sua história e sua força política junto a CAPES e CNPq a habilitam a desempenhar papel histórico fundamental 
na construção de uma estratégia para a área. Como associação, a ANPAD é o locus privilegiado onde todos os coordenadores podem exercitar a cidadania e promover o tipo de mestrado e doutorado em Administração que queremos. Tal vocação política da ANPAD depende dos coordenadores de curso, de sua participação ativa e efetiva nas assembleias e, é claro, da Diretoria, que pode e deve liderar o processo de dar voz aos programas junto às agências de fomento e de avaliação.

Finalmente, uma alternativa levantada no Painel sobre a Formação do Professor na PósGraduação em Administração e Contabilidade, realizado durante o Encontro da Divisão de Ensino e Pesquisa em Administração e Contabilidade da ANPAD, em Brasília, em 2013 merece menção para a institucionalização da linha de pesquisa em Ensino e Aprendizagem nos programas de pós-graduação. Retomando a sugestão de Fischer (2006, p.196), foi proposta a criação de uma linha de pesquisa com o foco em ensino e aprendizagem, podendo ser denominada de "Ensino e Aprendizagem em Administração", ou Ensino e Aprendizagem em alguma área específica ou em um tema transversal, como, por exemplo, "Ensino e Aprendizagem em Sustentabilidade", ou "Ensino e Aprendizagem em Estratégia".

Diz o atual Documento de Área de Administração, Contabilidade e Turismo (CAPES, 2013), tanto para Mestrado Acadêmico/Doutorado quanto para Mestrado Profissional, que:

cada linha de pesquisa deve contar com a participação de, no mínimo, quatro docentes permanentes [...] Os docentes permanentes podem ser compartilhados entre as linhas de atuação, mas o número mínimo de professores deve ser o número de linhas multiplicado por quatro. Portanto, uma proposta com, por exemplo, três linhas de atuação deve contar com 12 professores permanentes.

A sugestão é de que a linha de pesquisa (expressão utilizada para mestrados acadêmicos e doutorados) ou linha de atuação (expressão utilizada para mestrados profissionais) em Ensino e Aprendizagem em Administração/Contábeis/Turismo seja uma exceção para a contagem dos professores do Programa. Assim, a linha de pesquisa/atuação em Ensino e Aprendizagem teria, no mínimo, quatro docentes permanentes compartilhados ou não com outras linhas de pesquisa/atuação, porém ela não entraria na conta para o cálculo da quantidade mínima de professores permanentes. Assim, uma proposta com, por exemplo, 4 linhas de pesquisa - sendo uma delas a de Ensino e Aprendizagem em Administração - deve conter no mínimo 12 professores permanentes, observadas as condições de pelo menos 4 professores permanentes por linha de pesquisa/atuação que não seja a de "Ensino em Administração/Contabilidade". Tal 
proposta se justifica pelo fato de a maioria dos pesquisadores da área de Ensino e Pesquisa ser também filiada a outras áreas da Administração ou Contabilidade e pelo fato de tratar-se de um tema que perpassa cada uma das áreas da Administração.

Enfim, existem alternativas para promover a formação docente nos cursos de Administração. Elas dependem do exercício contínuo da problematização do tema, de vontade política e de participação ativa nos fóruns adequados. Com esse propósito, este ensaio almeja contribuir para a discussão do tema, do diagnóstico dos problemas e das possíveis alternativas para minimizá-los. Espera-se, assim, maior protagonismo na construção da pós-graduação que queremos e com que sonhamos. 


\section{REFERÊNCIAS}

AKTOUF, O. Ensino de administração: por uma pedagogia para mudança. In: Organização \& Sociedade, v. 12, n. 35, 151-159, out./dez.2005.

ADORNO, T.W. Educação e emancipação. São Paulo: Paz \& Terra, 1995.

ALCADIPANI. R. Academia e a fábrica de sardinhas In: Organização \& Sociedade, Salvador, v. 18, n. 57, p. 345-348, abr./jun., 2011.

ANASTASIOU, L. G. C. A docência no ensino superior: desafios e possibilidades. In: Ensino de graduação: desafios e perspectivas. For GRAD em Revista. Vitória, n. I, p. 5-8. 2006.

ANASTASIOU, L. G. C; ALVES, L. P. Estratégias de ensinagem. In: Processos de ensinagem na universidade. Joinville: Ed. Univille, 2003.

BARROS, K. S. M. O que é um Ensaio? Revista de Administração Contemporânea, Curitiba, v. 15, n. 2, p.333-337, mar./abr, 2011. Bimestral. Disponível em:

<http://www.anpad.org.br/periodicos/arq_pdf/a_1169.pdf>. Acesso em: 1 mar. 2011.

BASTOS, C. C. B. C. Docência, pós-graduação e a melhoria do ensino na universidade: uma relação necessária. In: Educere et Educare, v. 2, n. 4, p. 103-112, jul./dez. 2007.

BERTERO, C. O. O Que é um Ensaio Teórico? Réplica a Francis Kanashiro Meneghetti. Revista de Administração Contemporânea, Curitiba, v. 15, n. 2, p. 338-342, mar./abr., 2011.

Disponível em: <http://www.anpad.org.br/periodicos/arq_pdf/a_1169.pdf>. Acesso em: 1 mar. 2011.

BIANCHETTI, L.; MACHADO, A. M. N. Trabalho docente no stricto sensu: publicar ou morrer? In: FIDALGO, F.; OLIVEIRA, M. A. M.; Fidalgo, N. L. R.. (Org.). A intensificação do trabalho docente - tecnologias e produtividade. (2009) Campinas: Papirus, 2009.

BOURDIEU, P. Esquisse d'une théorie de la pratique. Genève: Droz, 1972.

BRASIL. Lei de Diretrizes e Bases da Educação Nacional de 1996. Disponível em: <http://portal.mec.gov.br/arquivos/pdf/ldb.pdf>. Acesso em: 10 de maio de 2011.

CAPES. Avaliação Trienal 2010: planilhas comparativas. 2009a. Disponível em: <http://www.capes.gov.br/images/stories/download/avaliacaotrienal/planilhascomparativastrienal 2010/Admin_CienContabeis_Tur.xls>. Acesso em: 23 fev. 2011.

CAPES. Relatório de Avaliação 2007-2009 - (Documento de Área), 2009b. Disponível em: <http://www.capes.gov.br/images/stories/download/avaliacao/ADMIN17jun10.pdf>. Acesso em: 23 fev. 2011.

CAPES. Relatório de divulgação dos resultados da avaliação trienal 2010. 2010 Disponível em: <http://trienal.capes.gov.br/wpcontent/uploads/2010/09/relatorio_geral_dos_resultados_da_avaliacao.pdf $>$. Acesso em: 23 fev. 2011.

CAPES. Documento de área e Comissão da Trienal 2013. (Documento de Área 2013). 2013. Disponível em: 
http://www.capes.gov.br/images/stories/download/avaliacaotrienal/Docs_de_area/Administra\%C 3\%A7\%C3\%A3o_doc_area_e_comiss\%C3\%A3o_16out.pdf . Acesso em: 23 out. 2013.

CENTRO DE GESTÃO E ESTUDOS ESTRATÉGICOS. Doutores 2010. Estudos da demografia de base técnico-científica brasileira. Brasília: CGEE, 2010.

CHAMLIAN, H. C. Docência na universidade: professores inovadores na USP. In: Cadernos de Pesquisa, São Paulo, v. 1, n. 118, p. 41-64, mar. 2003.

COHN, G. (org.). Max Weber. São Paulo: Ática, 1991.

CUNHA, M. I. Ensino como mediação da formação do professor universitário. In: MOROSINI, M. C. (org.) Professor do ensino superior: identidade, docência e formação. Brasília: Plano Editora, 2001.

CUNHA, M. I. O bom professor e sua prática. Campinas: Papirus, 2009.

CUNHA, M. I. Ensino com pesquisa: a prática do professor universitário In: Cadernos de Pesquisa, Fundação Carlos Chagas, São Paulo, n. 97, p. 31-46, maio 1996.

CURY, C. R, J. O debate sobre a pesquisa e a avaliação da pós-graduação em educação. Revista Brasileira de Educação [online], v. 15, n. 43, p. 162-165, 2010. Disponível em: <http://dx.doi.org/10.1590/S1413-24782010000100011>. Acesso em: 23 fev. 2011.

DEMO, P. Outro professor - alunos podem aprender bem com professores que aprendem bem. Judiai: Paco Editorial, 2011.

DEMO, P. Professor e seu direito de estudar. In: SHIGUNOV NETO, A. S.; MACIEL, L. S. B. (Orgs.). Reflexões sobre a formação de professores. Campinas: Papirus, 2002. P. 71-78

FERNANDES, C. M. B. Formação do professor universitário: tarefa de quem? In: MASETTO, M. (Org.). Docência na universidade. Campinas: Papirus, 1998. p. 95-112.

FESTINALLI, R. C. A Formação de Mestres em Administração: Por Onde Caminhamos? In: XXIX ENANPAD 2005, Brasília DF. Anais... Brasília: ANPAD, 2005

FICHTE, J. G. Por uma universidade orgânica. Rio de Janeiro: EdUERJ, 1999.

FIDALGO, N. L. R.; FIDALGO, F. (Org.). Trabalho Docente e Lógica Produtivista: conformação e subjetividade. In: FIDALGO, F.; OLIVEIRA, M. A. M.; FIDALGO, N. L. R. (Org.). A intensificação do trabalho docente - tecnologias e produtividade. Campinas: Papirus, 2009. p. 91-112.

FISCHER, T. Uma luz sobre as práticas docentes na pós-graduação: a pesquisa sobre ensino e aprendizagem em Administração. In: Revista de Administração Contemporânea, v. 10, n. 4, p. 193-197, out./dez. 2006.

GRILLO, M. C.; MATTEI, P. Saberes docentes, identidade profissional e docência. In: Enricone, D.; Grillo, M. (Org.) Educação Superior: vivências e visão de futuro. Porto Alegre:

EDIPUCRS, 2005.

GUSDORFF, G. Professores, para quê? Santos: Martins Fontes, 1970.

HUMBOLDT, W. Von. Sobre a organização interna e externa das instituições científicas superiores em Berlim. In: KRETSCHMER, J.; ROCHA, J. C. de C. (Org./Trad.). Um mundo sem universidades? Rio de Janeiro, EdUERJ, 1997. 
JOAQUIM, N. de F. Desafios da formação docente: estágio docência e a prática de ensino em Administração. Dissertação (Administração) - Universidade Federal de Lavras, Programa de Pósgraduação em Administração, 2011.

KUENZER, A. Z.; MORAES, M. C. M. Temas e tramas na pós-graduação em educação. Educação e Sociedade, v. 26, n. 93, p. 1.341-1.362, 2005.

LIBÂNEO, J.C. Reflexividade e formação de professores: outra oscilação no pensamento pedagógico brasileiro. In: PIMENTA, S. G.; GHEDIN, E. (Org.). Professor reflexivo no Brasil: gênese e crítica de um conceito. São Paulo: Cortez, 2002.

MACEDO, D. V., PAULA, E.; Torres, B. B. Formação pedagógica dos estudantes de pósgraduação. Campinas: Unicamp: São Paulo: USP, 1998. (Trabalho não publicado).

MACHADO, A. M. N.; BIANCHETTI, L. (Des)fetichização do produtivismo acadêmico: desafios para o trabalhador-pesquisador. Revista de Administração de Empresa [online], v. 51, n. 3, p. 244-254, 2011. Disponível em: <http://dx.doi.org/10.1590/S0034-75902011000300005>. Acesso em: 1 mar. 2011.

MARANHÃO, C. M. S. de. A. Indústria cultural e semiformação - análise crítica da formação dos administradores. Tese (Administração) - Universidade Federal de Minas Gerais, Centro de Pós-Graduação e Pesquisa em Administração, 2010.

MASETTO, M. Competência pedagógica do professor universitário. São Paulo: Summus, 2003.

MASETTO, M. (Org.). Docência na universidade. Campinas: Papirus, 1998.

MENEGHETTI, F. K. O que é um Ensaio-Teórico? Revista de Administração

Contemporânea, Curitiba, v. 15, n. 2, p. 320-332, mar./abr. 2011. Disponível em:

<http://www.anpad.org.br/periodicos/arq_pdf/a_1169.pdf>. Acesso em: 1 mar. 2011.

MENEGHETTI, F. K. Tréplica - O que é um Ensaio-Teórico? Tréplica à Professora Kazue Saito Monteiro de Barros e ao Professor Carlos Osmar Bertero. Revista de Administração

Contemporânea, Curitiba, v. 15, n. 2, p. 343-348, mar./abr., 2011. Disponível em: <http://www.anpad.org.br/periodicos/arq_pdf/a_1169.pdf>. Acesso em: 1 mar. 2011.

MOROSINI, M.C. Docência universitária e os desafios da realidade educacional. In: MOROSINI (Org.) Professor do ensino superior - identidade, docência e formação. Brasília: INEP, 2000.

NASCIMENTO, L. F. Modelo Capes de avaliação: Quais as consequências para o triênio 20102012? Administração: Ensino e Pesquisa, Rio de Janeiro, v. 11, n. 4, p. 579-600, 2010.

Disponível em: 〈http://www.angrad.org.br/_resources/_circuits/article/article_548.pdf〉. Acesso em: 10 mar. 2011.

NICOLINI, A. Qual será o futuro das fábricas de administradores? Revista de Administração de Empresa, n. 2, v. 43, p. 44-54, 2003.

PACHANE, G. G; PEREIRA, E. M. A importância da formação didático-pedagógica e a construção de um novo perfil para docentes universitários In: Revista Iberoamericana de Educación, n. 33, jul. 2004. Disponível em: 〈http://www.rieoei.org/deloslectores/674Giusti107.PDF〉. Acesso em: 10 mar. 2011. 

profissional reflexivo. In: NÓVOA, A. Os professores e sua formação. Lisboa: Dom Quixote, 1992.

PIAGET, J. Epistemologia genética. Lisboa: Martins Fontes, 2007.

PIMENTA, S.; ANASTASIOU, L. G. C. Docência em Formação no Ensino Superior. São Paulo: Cortez, 2002.

PITA, M. Estresse laboral, assédio moral e burnout marcam produtivismo. Revista ADUSP, São Paulo, n. 48, p. 14-21, set. 2010.

RIBEIRO, R. J. Humanidades - um novo curso na USP. São Paulo: Edusp, 2000.

SACRISTÁN, G. J. O currículo modelado pelos professores. In: O Currículo: uma reflexão sobre a prática. Porto Alegre: Artmed, 1998.

SCHÖN, D. Educando o profissional reflexivo: um novo design para o ensino e a aprendizagem. Porto Alegre: Artmed, 2000.

SCHÖN, D. Formar professores como profissionais reflexivos. In: NÓVOA, A. Os professores e sua formação. Lisboa: Dom Quixote, 1992.

SGUISSARDI, V. Produtivismo acadêmico. In: OLIVEIRA, D. A.; DUARTE, A. M. C.; VIEIRA, L. M. F. (Org.). Dicionário de trabalho, profissão e condição docente. Belo Horizonte: Faculdade de Educação/UFMG, 2010.

SINAES. Da concepção à regulamentação. 5. ed. rev. ampl. Brasília: Inep, 2009.

SOUZA-SILVA, J.C.; DAVEL, E. Concepções, práticas e desafios na formação do professor: examinando o caso do ensino superior de administração no Brasil. In: Organização \& Sociedade, v. 12, n. 35, out./dez.2005.

SPAGNOLO, F.; CALHAU, M.G. Observadores internacionais avaliam a avaliação da CAPES. Infocapes, v. 10, n. 1, p. 7-34, 2002.

SPAGNOLO, F; SOUZA, V. P. O que mudar na avaliação da Capes? Revista Brasileira de PósGraduação, v. 1, n. 2, p. 8-34, 2004.

SPINK, P. K.; ALVES, M. A. O campo turbulento da produção acadêmica e a importância da rebeldia competente. Organização \& Sociedade, Salvador, v. 18, n. 57, p. 337-343, abr./jun., 2011.

TEIXEIRA, D. J.; OLIVEIRA, C. C. G.; FARIA, M. A. O perfil dos egressos do Programa de Mestrado Profissional em Administração da PUC Minas / FDC no período de 2000 a 2005. $1^{\circ}$ ENCONTRO DE ENSINO E PESQUISA EM ADMINISTRAÇÃO E CONTABILIDADE. Recife/PE - 21 a 23 de novembro de 2007. Anais... Recife: EnEPQ, 2007.

TREIN, E.; RODRIGUES, J. O mal-estar na academia: produtivismo científico, o fetichismo do conhecimento-mercadoria. Revista Brasileira Educação [online], v. 16, n. 48, p. 769-792, 2011. Disponível em: <http://dx.doi.org/10.1590/S1413-24782011000300012>. Acesso em: 10 mar. 2011.

VYGOTSKY, L. S. Pensamento e linguagem. São Paulo: Martins Fontes, 1989. 

INSTITUTO DE ESTUDOS E PESQUISAS EDUCACIONAIS "ANÍSIO TEIXEIRA" (INEP). Brasília, 2005. Disponível em: 〈www.naeg.prg.usp.br/gap/secoes/seminario/docencia_universitaria_na_educacao_superior.pdf> Acesso em: set. 2009.

ZABALZA, M. A. Competencias docentes del profesorado universitário: calidad y desarrollo profesional. Madri: Narcea, 2004.

ZANCHETY, B. M. B.A.; GHIGGI, M. Docencia universitaria: formación y aprendizaje en el posgrado en educación. Revista Educação Superior [online], v. 38, n. 151, p. 163-170, 2009. Disponível em: <http://www.scielo.org.mx/scielo.php?script=sci_arttext\&pid=S0185$27602009000300009 \& \operatorname{lng}=\mathrm{es} \& n r m=\mathrm{iso}>$. Acesso em: abr. $/ 2011$. 